\title{
Investigating the Effects of Temperature, Paste Height and Time on the Rolling of Solder Paste
}

\author{
EKE J., Okafor P.U. and Arinze S.N. \\ Department of Electrical and Electronic Engineering \\ Enugu State University of Science and Technology, Nigeria.
}

\begin{abstract}
Based on application, it was found that the rheological properties of the solder paste play an important role in the print performance. Temperature-dependent rheological behaviour of the lead-free solder paste and flux medium used for flip-chip assembly applications were studied. Two commercially available lead-free solder pastes P1 (LF318) and P2 (LF328) prepared from fluxes F1 and F2 were used. The temperatures under investigation were $15^{\circ} \mathrm{C}, 25^{\circ} \mathrm{C}$, and $35^{\circ} \mathrm{C}$. All the results recorded were put into the Gauge calculator. The snap-off height variable and the condition of the printing equipment were used to determine the print height. Slump test was used to determine the slumping behaviour at room temperature and during reflow. Results show that the properties of solder paste are immensely affected by paste heights, high temperature variations, time and humidity.

Keywords: Surface Mount Technology (SMT), Printed Circuit Board (PCB) Assembly, Slump Test, Reflow Soldering, Solder Paste.

DOI: $10.7176 /$ ISDE/11-1-05

Publication date: February $29^{\text {th }} 2020$

\section{Introduction}

According to Ray, (1997) the current methodological approach of manufacturing conventional electronic assemblies have essentially reached their limits when cost, weight, volume, and reliability are considered. Surface mount technology (SMT) makes it possible to achieve reliability in producing more assemblies at reduced weight, volume and cost. Basically, SMT is used to mount electronic components on the surface of PCBs or substrates. Thus as the trend toward miniaturization and compact product continues, the assembling process of the electronic component or surface mount devices (SMDs) becomes more complex and there is a need for some form of automation (Lau et al. 1996). In other words, the automated process of assembling the electronic component or surface mount devices is known as SMT by means of using solder paste as interconnecting material to provide electrical, thermal and mechanical function (Huang et al, 2002, and Nguty et al, 2001).
\end{abstract}

Greater percentage of the components used on a printed circuit board assembly (PCBA) are based on surface mount technology (SMT) being assembled using solder paste printing (SPP) and then fixed by the reflow soldering (RS) process (Lau and Yeung, 1996). There are three major challenges in the fine pitch stencil printing process. These challenges are the solder paste formulation, the stencil manufacturing process and the optimisation of the process parameters in stencil printing. Stencil printing account for a great percentage of defects in SMT. One of the major courses of these defects is the solder paste behaviour during stencil printing, which is greatly affected by many parameters such as temperature, time, height of paste and viscosity. Apparently, it is necessary to embark on an intensive study on the effects of not only the temperature (Durairaj et al, 2002) but, time and paste height on solder paste with respect to its printing performance.

\section{Methodology}

Two commercially available lead-free solder pastes P1 (LF318) and P2 (LF328) prepared from fluxes F1 and F2 were used as shown in Figure 1. The solder particles for all the paste samples are made of the same tin-silvercopper alloy with a melting point of $217^{\circ} \mathrm{C}$. Both $\mathrm{P} 1$ and $\mathrm{P} 2$ have a percentage metal loading of $88.5 \%$. P1 is a Type 3 solder paste and P2 is Type 4 . The flux medium makes up for $11.5 \%$ of the solder paste weight. The flux medium contains a stable resin system and slow evaporating solvents with minimal odour. The formulation meets the requirements of the Telcordia (formerly known as Bellcore) GR-78-CORE and ANSI/J-STD-004 for a type ROL0 classification. 

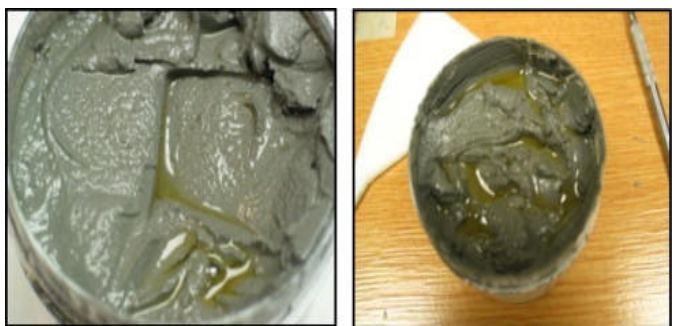

Figure 1: Lead-free Solder Paste LF318 and LF328

The two lead-free solder pastes LF318 and LF328 used were separated into nine different jars respectively, making it eighteen jars in a whole. Each jar contained one hundred grams of lead-free solder paste. This separation was to allow for the number of experiments that was carried out in the study. For quick and easy identification, LF318 was named P1 and LF328 was named P2. The temperatures under investigation were $15^{\circ} \mathrm{C}, 25^{\circ} \mathrm{C}$, and $35^{\circ} \mathrm{C}$. As shown in table 1, two solder pastes P1 and P2 were stored at each of these temperatures for 24hours, 48hours, and 72 hours respectively, making it nine experiments for each solder paste.

Table 1: Storage parameters for $\mathrm{P} 1$ and $\mathrm{P} 2$ at the thermal chamber.

\begin{tabular}{|l|l|l|l|l|}
\hline Solder paste & Temperature ('C) & $\begin{array}{l}\text { Storage time } \\
(\text { minutes })\end{array}$ & $\begin{array}{l}\text { Storage time } \\
\text { (minutes) }\end{array}$ & $\begin{array}{l}\text { Storage time } \\
\text { (minutes) }\end{array}$ \\
\hline P1 & $15\left({ }^{\circ} \mathrm{C}\right)$ & 1440 & 2880 & 4320 \\
\hline P2 & $15\left({ }^{\circ} \mathrm{C}\right)$ & 1440 & 2880 & 4320 \\
\hline P1 & $25\left({ }^{\circ} \mathrm{C}\right)$ & 1440 & 2880 & 4320 \\
\hline P2 & $25\left({ }^{\circ} \mathrm{C}\right)$ & 1440 & 2880 & 4320 \\
\hline P1 & $35\left({ }^{\circ} \mathrm{C}\right)$ & 1440 & 2880 & 4320 \\
\hline P2 & $35\left({ }^{\circ} \mathrm{C}\right)$ & 1440 & 2880 & 4320 \\
\hline
\end{tabular}

\section{Process parameters}

The printing parameters used for the experiment are outlined in table 2. Previous work reported by Marks et al (2007) was used as a benchmark.

Table 2: Printing parameters

\begin{tabular}{|c|c|}
\hline Pinting parameters & Valuseswed \\
\hline Priming Solperseres peed & Dnmosec \\
\hline 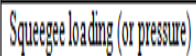 & digg \\
\hline Seppation noped & $100 \%(3)$ m \\
\hline Shappotithing gap & 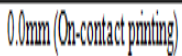 \\
\hline
\end{tabular}

4.0 Experimental result

All the results recorded were put into the Gauge calculator. The R\&R\% got was $19.43 \%$. This is well below $30 \%$ which is the acceptable standard. This means that the measurement device is capable of the task.

\subsection{Plotting the average}

In the formation of solder joints, print thickness determines the volume of solder in the joint. The thickness of the paste print is determined by the thickness of the metal mask of the stencil. Though stencil thickness controls the paste thickness, other variables such as snap-off height and the condition of the printing equipment determine the print height. The reflow solder height is not just a factor of solder paste height only, but also the metal content of the paste. Due to the fact that the print gap for the experiment is $0.0 \mathrm{~mm}$, the snap-off height becomes the thickness of the stencil which is $125 \mu \mathrm{m}$. Therefore at this stage, the average of the average heights got from the regions in the chosen locations on the stencil was computed.

In each of the two locations under investigation, four regions were measured. In each region, two deposits were measured. The averages of the two deposits were taken. Subsequently, the averages of the locations were then 
computed based on the four regions. A sample of the 3-D image of the measured heights is shown in Figures 2 and 3 . Figure 2 shows the height of P1 while Figure 3 shows that of P2

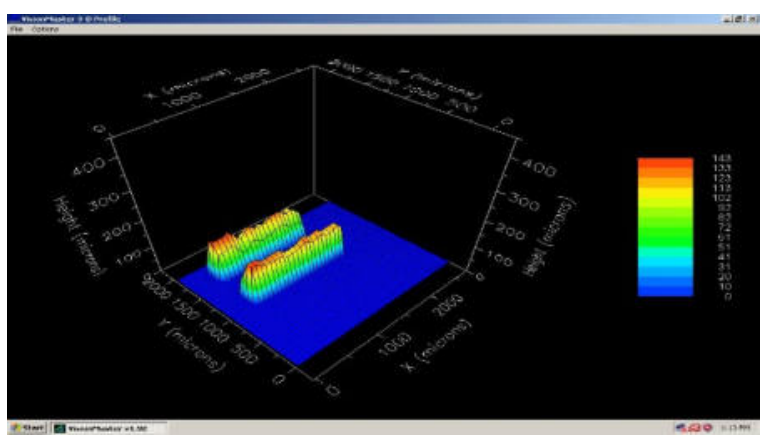

Figure 2: Image of the Solder Paste Deposit for Location 1

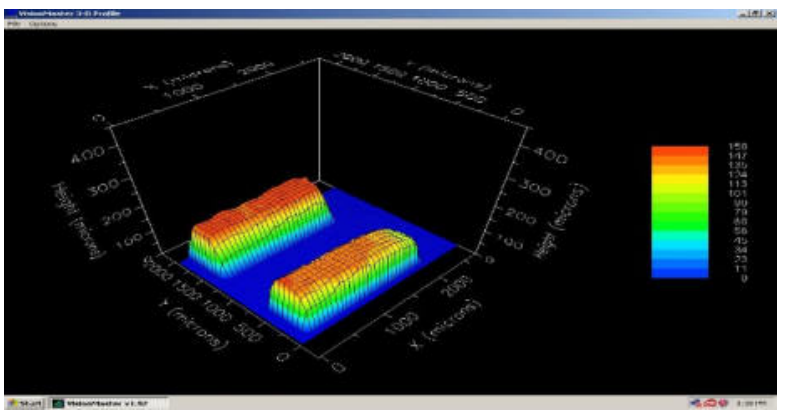

Figure 3: Image of the Solder Paste Deposit for Location 2

The blue base indicates the reference point, which is surface of the substrate. The red colour indicates maximum height. The results from the computed averages are shown in Tables 3 and 4, while Figures 4 and 5 show the graphs of the computed average height against the solder paste storage/aging time with respect to the storage temperatures.

Table 3: Results for solder paste deposit heights for LF318.

\begin{tabular}{|l|l|l|l|l|l|}
\hline LF318 = P1 & $\begin{array}{l}\text { Storage time } \\
\text { temperature }\left({ }^{\circ} \mathrm{C}\right)\end{array}$ & $\begin{array}{l}\text { Target } \\
\text { height } \\
(\mu \mathrm{m})\end{array}$ & $\begin{array}{l}\text { Height fors } \\
\text { Location } \\
(\mu \mathrm{m})\end{array}$ & $\begin{array}{l}\text { Height for } \\
\text { Location } \\
(\mu \mathrm{m})\end{array}$ & $\begin{array}{l}\text { Average } \\
\text { height }(\mu \mathrm{m})\end{array}$ \\
\hline 15 & 24 & 125 & 103.36 & 89.5 & 96.43 \\
\hline 15 & 48 & 125 & 91.63 & 109.66 & 100.65 \\
\hline 15 & 72 & 125 & 92.24 & 115.9 & 104.07 \\
\hline 25 & 24 & 125 & 89.15 & 115.58 & 102.37 \\
\hline 25 & 48 & 125 & 83.48 & 122.74 & 103.11 \\
\hline 25 & 72 & 125 & 102.08 & 116.79 & 109.44 \\
\hline 35 & 24 & 125 & 100.25 & 120.15 & 110.2 \\
\hline 35 & 48 & 125 & 95.26 & 118.69 & 106.98 \\
\hline 35 & 72 & 125 & 112.02 & 119.43 & 115.74 \\
\hline
\end{tabular}




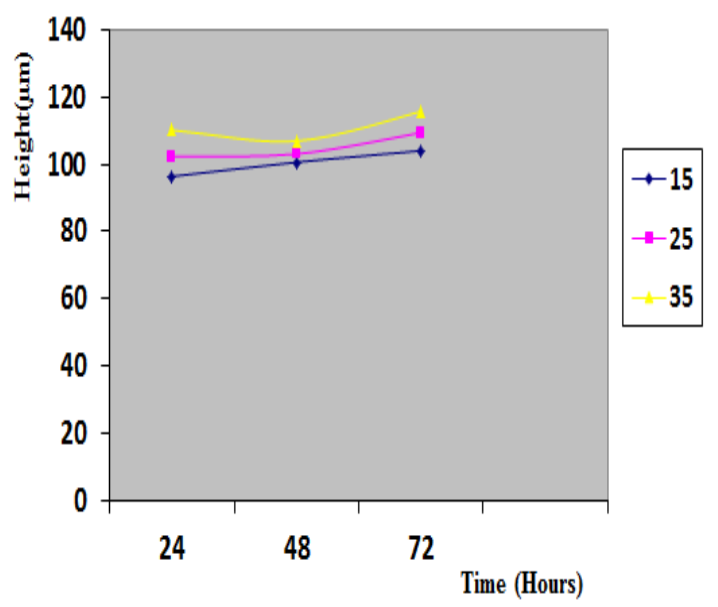

Figure 4: Average Height against the Solder Paste Storage/Aging Time With Respect To the Storage Temperatures for LF318.

Table 4: Results for solder paste deposit heights for LF328

\begin{tabular}{|l|l|l|l|l|l|}
\hline LF328 = P2 & $\begin{array}{l}\text { Storage time } \\
\text { Storage } \\
\text { temperature }\left({ }^{(} \mathrm{C}\right)\end{array}$ & $\begin{array}{l}\text { Target } \\
\text { height } \\
(\mu \mathrm{m})\end{array}$ & $\begin{array}{l}\text { Height for } \\
\text { Location } \\
(\mu \mathrm{m})\end{array}$ & $\begin{array}{l}\text { Height } \\
\text { Location } \\
(\mu \mathrm{m})\end{array}$ & $\begin{array}{l}\text { for } \\
2\end{array}$ \\
\hline 15 & 24 & 125 & 120.83 & 103.06 & $\begin{array}{l}\text { Average } \\
\text { height }(\mu \mathrm{m})\end{array}$ \\
\hline 15 & 48 & 125 & 89.63 & 111.95 \\
\hline 15 & 72 & 125 & 92.24 & 109.66 & 99.93 \\
\hline 25 & 24 & 125 & 108.5 & 126.26 & 96.76 \\
\hline 25 & 48 & 125 & 98.49 & 102.08 & 117.38 \\
\hline 25 & 72 & 125 & 100.21 & 11538 & 100.29 \\
\hline 35 & 24 & 125 & 99.63 & 114.48 & 107.06 \\
\hline 35 & 48 & 125 & 110.15 & 133.9 & 122.03 \\
\hline 35 & 72 & 125 & 117.14 & 129.48 & 123.31 \\
\hline
\end{tabular}

After 24hours aging

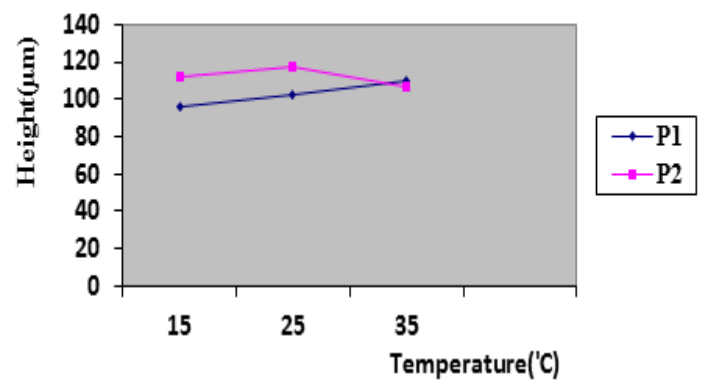

Figure 5: Average Height against the Solder Paste Storage/Aging Time With Respect To the Storage Temperatures for LF328

During the printing process for LF318 aged at $15^{\circ} \mathrm{C}$ for 24 hours, the solder paste just rolled minimally. The temperature of the solder paste during the printing was low, and that had a great effect on the solder paste viscosity. The low temperature made the solder paste viscosity to be too high. The temperature was not conducive for the rheological properties of the solder paste to be at its best. Therefore, the paste could not role, giving rise to skipping and low aperture filling which in effect caused ragged edges. This was one of the contributing factors to the low height seen after the printing. This is evident from the points of the height for $15^{\circ} \mathrm{C}$ in Figure 2 .

It can be observed that as the temperature increased, the height against time also increased. This trend was seen for both P 1 and P 2, except for P 2 stored at $35^{\circ} \mathrm{C}$ for 24 hours. Normally, it would be expected that increase in temperature would give rise to decrease in height, given that higher temperature would cause the solder paste to 
slump. Rather than decrease the height as the temperature increased, the height was increasing. This is because at low temperature, the paste's viscosity increases causing the solder paste flow to slow down or not to flow at all.

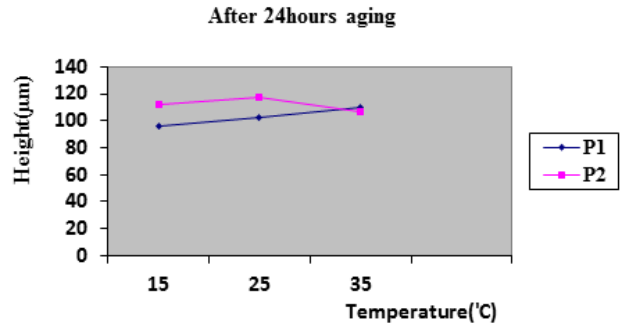

Figure 6 (i): Comparing solder paste deposit heights of P 1 and P 2 for 24 hours aging. After 48 Hours aging

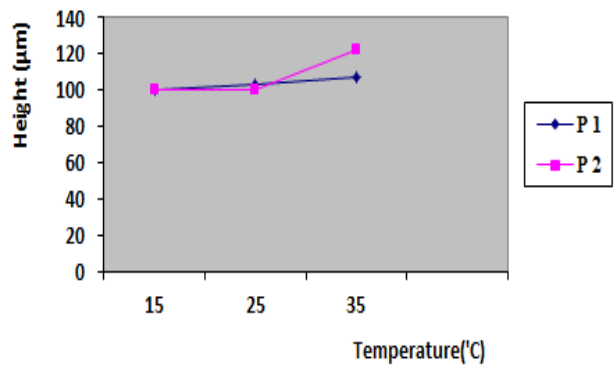

Figure 6 (ii): Comparing solder paste deposit heights of P 1 and P 2 for 48 hours aging

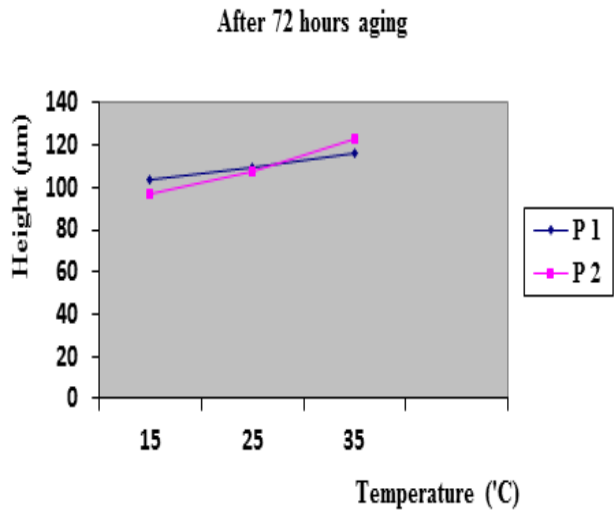

Figure 6 (iii): Comparing solder paste deposit heights of P 1 and P 2 for 72 hours aging

When the solder pastes were compared, it was found as shown in Figures 6 (i), (ii), and (iii) that the height increases as the temperature increases. This trend was seen as earlier discussed, for all the experiments except for P2 aged/conditioned at $35^{\circ} \mathrm{C}$ for 24 hours. This shows that increase in height with increase in temperature and or storage time is common for both P1 and P2. Judging from common trend of increased height with increased temperature, the behaviour of $\mathrm{P} 2$ conditioned at $35^{\circ} \mathrm{C}$ for 24 hours may be a special cause of variation.

Considering the relationship between paste heights, ability of the solder paste to roll during printing, viscosity, temperature and time, the results got in this experiment was compared with that got by Nguty and Ekere (2000). It was shown that there was an increase of $60 \%$ in paste viscosity for samples kept at room temperature apparently, longer time and higher temperature increases viscosity thereby increasing the tendency of the solder paste to roll. However, the temperature must not be excessive.

\subsection{Slump Test Results}

Lee (2002) stated that slump is a phenomenon where the paste viscosity is not high enough to resist the collapsing force exerted by gravity, and consequently results in spreading beyond the area to be deposited. Cold slump was 
used to determine the solder paste behaviour. Cold slump refers to the slumping behaviour at room temperature while hot slump refers to slumping during reflow. Figure 7 shows the slump location that was visually observed using a Leica S6D zoom stereomicroscope. From the observations, paste stored at $35^{\circ} \mathrm{C}$ had the highest level of slumping.
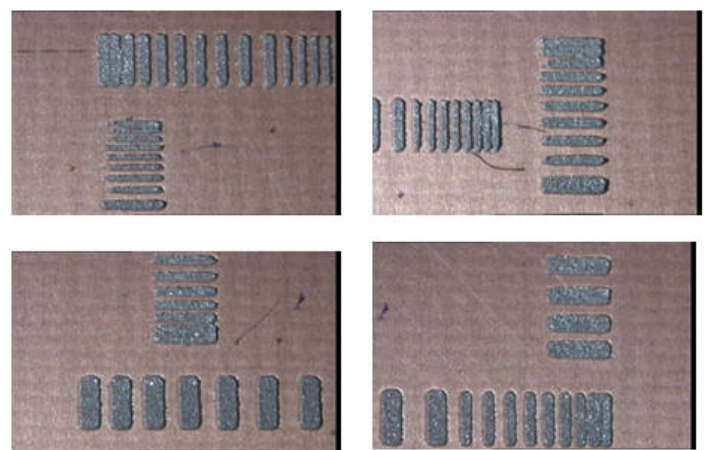

Figure 7: Four Edges of the Slump Location for P1

\section{Conclusion}

Considering the slumping behaviour of solder paste, it was believed that the height of the solder paste would decrease as the temperature increased. But this was not obvious, the height rather increased slightly as the temperature increased. This behaviour was as a result of some factors. First, paste was not able to role at low temperatures such $15^{\circ} \mathrm{C}$. Secondly, as the temperature increased, the paste rolled and was able to fill the apertures effectively. Therefore, considering this slumping phenomenon, the paste stored at $25^{\circ} \mathrm{C}$ for 48 hours produced the best results of good height with minimal slumping. The solder paste can be identified by its properties such as viscosity, normal force, density and surface tension when considered as a homogeneous and kinetically stable mixture. Considering the relationship between paste heights, ability of the solder paste to roll during printing, viscosity, temperature and time, the results achieved was compared and it was shown that there was an increase of $60 \%$ in paste viscosity for samples kept at room temperature apparently, longer time and higher temperature increases viscosity thereby increasing the tendency of the solder paste to roll. From the analysis, it is obvious that temperature, height and time have tremendous effects on the rolling of solder paste.

\section{References}

Clements, D., Desmulliez, M. P. Y. and Abraham, E (2007), "The evolution of paste pressure during stencil printing”, Soldering and Surface Mount Technology, 19, 3, pp. 9 -14.

Colin C. Johnson and Joseph Kevra (1989). Solder paste technology: principles and applications. Edition: Illustrated. Publisher TAB Professional and Reference Books.

Durairaj, R, Ekere, N. N. and Salam, B. (2004), "Thixotropy flow behaviour of solder and conductive adhesive pastes", Journal of materials science: materials in electronics, 15, $677-683$.

Durairaj, R, Nguty, T. A. and Ekere, N. N. (2001), "Critical Factors Affecting Paste Flow During Stencil Printing of Solder Paste", Soldering and Surface Mount Technology, 13, 2, pp $30-34$..

John H. Lau, C. P Wong, Ning-Cheng Lee, S. W Ricky Lee (2002). Electronics manufacturing: with lead-free, halogen-free, and conductive-adhesive materials. Edition: illustrated. Published by McGraw-Hill Professional. ISBN: 0071386246, 9780071386241

Lau, F. K. H. and Yeung, V. W. S., (1997), “A hierarchical evaluation of the solder paste printing process”, Journal of Materials Processing Technology, Vol. 69 pp. 79-89

Lee, N. C. (2002), "Reflow Soldering Processes: SMT, BGA, CSP and Flip-Chip Technologies", Newnes Publication, USA, pp. 41 - 44, 101 - 103. Available at: http://books.google.co.uk/books?id=Tv_AuIPrZmEC (accessed 17 March 2008). 
Leo P. Lambert (1988). Soldering for Electronic Assemblies. Edition: Illustrated. Published by Marcel Dekker. ISBN: $082477681 X, 9780824776817$

Marks, A., Mallik, S., Durairaj, R. and Ekere, N. N. (2007), 'Effect of Abandon Time on Print Quality and Rheological Characteristics for Lead-Free Solder Pastes used for Flip-Chip Assembly', 32nd International Electronics Manufacturing Technology Symposium (IEMT 2007) October 3-5 2007, San Jose/Silicon Valley, California, USA

Ekere N. N and Mallik S., (2008). A methodology for Characterising New Lead-Free Solder Paste Formulations used for Flip-chip Assembly Applications. Smart Processing Technology. 2 (1), 59-64.

Nguty, T. A. and Ekere, N. N. (2000), "The rheological properties of solder and solar pastes and the effect on stencil printing”. Rheologica Acta, 39, $607-612$.

Puttlitz, K. L. and Stalter, K. A. (2004), "Handbook of Lead-free Solder Technology for Microelectronic Assemblies", Marcel Dekker, New York, p 503, Available at: http://books.google.co.uk/books?id=H75TywRXUK4C (accessed 09 August 2009).

Durairaj R., Mallik S. and Ekere N. N., (2008). "Solder paste characterisation: towards. Soldering \& Surface mount technology”. 20 (3), 34-40. Emeral Group Pulishing limited. ISSN: 0954-0911

Durairaj R., Mallik S., Marks A., Winter M., Bauer R. and Ekere N.N, (2006). "Rheological Characterisation of New Lead-Free Solder Paste Formulations for Flip-Chip Assembly". Electronics Manufacturing Engineering Research Group Medway School of Engineering, University of Greenwich Chatham Maritime

Durairaj R., Ramesh S., Mallik S., Seman A., Ekere N. N. (2009). Rheological characterisation and printing performance of $\mathrm{Sn} / \mathrm{Ag} / \mathrm{Cu}$ solder pastes. Material and Design. 30 (3), 3812-3818.

Mallik S., Ekere,N. N., Durairaj R. and Marks A. E., (2008). An investigation into the rheological properties of different lead-free solder paste for surface mount application. Soldering \& Surface mount technology. 3-10. Emerald Group publishing limited. ISSN: 0954-0911

Nguty T., and Ekere N. N., (2000). Modelling the effects of temperature on the rheology of solder paste and flux system. Journal of material science: materials in Electronics. 11 (1), 39-43.

Ray P. P. (1997). “Surface Mount Technology”. ISBN : 978-0-412-12921-6 